\title{
You, Me, and Them: Understanding Employees' Use of Trans-Affirming Language within the Workplace
}

\author{
Francisco Perales $^{1,2}$ (C) Christine Ablaza ${ }^{1,2} \cdot$ Wojtek Tomaszewski ${ }^{2,3} \cdot$ Dawn Emsen-Hough $^{4}$
}

Accepted: 13 May 2021 / Published online: 31 May 2021

(c) The Author(s) 2021

\begin{abstract}
Introduction As the benefits of workplace inclusion become progressively recognized, employers are making greater efforts to cultivate inclusive organizational environments where employees from diverse backgrounds can thrive. Yet academic research has often neglected issues of sexual orientation and gender diversity. We contribute to redressing this knowledge gap by examining processes of workplace inclusion for employees with diverse genders and sexualities, focusing on an under-researched area-the role of language.

Methods Using a regression framework, we empirically examine how different individual and workplace factors are associated with employees' inclusive language use toward their trans- and gender-diverse colleagues. To accomplish this, we undertook the first-ever analyses of unique survey data from the 2020 Australian Workplace Equality Index Employee Survey ( $n \sim 27,000$ employees and $\sim 150$ employers).

Results Our results highlight the role of employees' socio-demographic characteristics (e.g., their gender and sexual orientation, age, education, and religiosity) as well as the role of features of the workplace environment (e.g., employer's size, location, and inclusion culture).

Conclusions While use of appropriate language toward individuals with diverse genders and sexualities constitutes an important stepping stone to their workplace inclusion, this study has demonstrated that its adoption remains incomplete and highly segmented.

Social Policy Implications These findings bear important implications for the design, targeting, and implementation of programs aimed at fostering trans-affirming language and the workplace inclusion of individuals from sexual and gender minorities.
\end{abstract}

Keywords Diversity · Inclusion · Language $\cdot$ Transgender · Gender diversity · Workplace

\section{Introduction}

The benefits of workplace diversity and, particularly, workplace inclusion are progressively recognized by academics and employers alike (Mor Barak, 2015). As a result,

Francisco Perales

f.perales@uq.edu.au

1 School of Social Science, The University of Queensland, Level 4 Michie Building, St Lucia, Brisbane, QLD 4072, Australia

2 ARC Centre of Excellence for Children and Families Over the Life Course, Institute for Social Science Research, The University of Queensland, Brisbane, QLD, Australia

3 Institute for Social Science Research, The University of Queensland, Brisbane, QLD, Australia

4 Pride in Diversity, ACON Health, Sydney, NSW, Australia employers across sectors are making greater and more concerted efforts to cultivate inclusive organizational environments where employees from both majority and minority social groups thrive (Ferdman, 2014). Academic research is well-placed to guide these efforts; for example, by empirically elucidating the individual- and structural-level factors that foster or inhibit processes of workplace inclusion. However, the bulk of the existing scholarship on diversity and inclusion has focused on socio-demographic traits such as age, gender, and ethnicity (Jackson et al., 2003), whereas other important personal qualities-such as sexual orientation and gender diversity-remain relatively underresearched (Day \& Greene, 2008).

In this paper, we contribute to filling this gap in scholarly knowledge by providing a better understanding of the factors that contribute to the workplace inclusion of employees with diverse genders and sexualities. This is an important 
endeavor, as individuals from both sexual minorities (e.g., those who identify as gay, lesbian, bisexual, pansexual, asexual, etc.) and gender minorities (e.g., those who identify as trans, binary or non-binary) experience comparatively poor labor-market outcomes (Badgett et al., 2007). Further, their suboptimal outcomes in the realm of work compound with their generally higher levels of social disadvantage in other life domains, including education (Birkett et al., 2014), health and wellbeing (Institute of Medicine, 2011), and family life (Reczek, 2020). Previous scholarship on workplace inclusion among members of these social groups has concentrated on discrimination throughout the employment process (e.g., hiring, promotions, and termination) (Drydakis, 2019) as well as harassment and bullying within the workplace (Collins et al., 2015). Here, we focus on an aspect that has received comparatively little attention-the role of language within the workplace.

As we elaborate on below, language can serve as a powerful tool for both inclusion and exclusion, in the workplace and elsewhere (Diversity Council Australia, 2016). Language constitutes a core component of most of our everyday written and verbal interactions (Collins \& Clément, 2012), and conventions about what constitutes appropriate language in the public sphere are in constant flux. In recent years, there have been substantial changes in language-related expectations in relation to individuals from some sexual and gender minorities. This applies for example to trans men and women, who may legally or socially change their name and/or align their personal pronouns to affirm their gender (Zimman, 2017). It pertains also to a growing number of people who identify as gender diverse and who often utilize gender-neutral personal pronouns that differ from those assigned at birth (e.g., "they/ them" pronouns). Research studies have demonstrated that being addressed by the correct name and personal pronouns has important positive repercussions for the mental health and feelings of workplace inclusion of trans and gender-diverse employees (Budge et al., 2010; Thoroughgood et al., 2020). However, there is also emerging evidence indicating that many employees remain unwilling, hesitant, or uncomfortable to change the language that they use to refer to their trans and gender-diverse colleagues (Grant et al., 2011). Which employees are comfortable with changing their language to make these colleagues feel included, and which are not, remains an open question.

In the remainder of this paper, we theorize and subsequently test the individual and workplace factors that are associated with employees' use of inclusive language toward their trans and gender-diverse colleagues. Enhancing our knowledge on these factors is timely and important, as it can meaningfully contribute to the design and implementation of programs and policies to foment the workplace inclusion of individuals with diverse genders and sexualities. As explained below, a feature that distinguishes our research from earlier efforts to interrogate processes of workplace inclusion among gender and sexual minorities is our reliance on quantitative methods. Specifically, we are able to undertake first-time academic analyses of an internationally unique survey that collects rich information on workplace inclusion from a large sample of Australian employees from multiple employers and sectors (the 2020 Australian Workplace Equality Index Employee Survey, $n \sim 27,000$ employees and $\sim 150$ employers). These unique data enabled us to provide a rare overview of the individual and organizational factors that act as enablers of, or barriers to, trans-affirming language use within the workplace.

While we recognize that some individuals may identify as "gender non-conforming," "gender non-binary," or "gender diverse" rather than explicitly as "trans," for parsimony; hereon, we use the umbrella term trans as a shorthand to refer to individuals whose gender identity differs from the sex they were assigned at birth. Where specificity is required, we use the qualifier "binary" to refer to trans people who identify as men or women, and the qualifier "non-binary" to refer to trans people who do not.

\section{Literature Review}

\section{Diversity and Inclusion in the Workplace}

The term diversity refers to "differences between individuals on any attributes that may lead to the perception that another person is different from the self" (Roberge \& van Dick, 2010, p.296). This includes perceived differences based on readily observable traits (e.g., age, sex, and race/ethnicity) and less easy-to-observe attributes (e.g., religion or sexual orientation) (Mor Barak, 2015; Roberge \& van Dick, 2010). Achieving a diverse workforce means that members of different groups across these social divisions are adequately represented within the organization.

The benefits of workplace diversity are increasingly recognized and supported by a robust body of research. Diversity can provide organizations with a competitive advantage in recruitment, customer service, and research and innovation (Cox, 1994; Mor Barak et al., 2016) and has been empirically linked to improvements in employee job satisfaction (Acquavita et al., 2009), creativity and problemsolving skills (Richard et al., 2013), and commitment and retention (Giffords, 2009; Groeneveld, 2011). Furthermore, having a diverse workforce can be seen as exercising social responsibility, as it contributes to empowering marginalized social groups (Mor Barak, 2015; Mor Barak et al., 2016), while also enhancing corporate image (Cox, 1994). However, diversity is not universally associated with positive outcomes, with some studies reporting links to intergroup conflict, workplace dissatisfaction, and decreased cooperation 
(Jackson et al., 2003; Mor Barak et al., 2016; Roberge \& van Dick, 2010).

These contradictory findings have been reconciled by recognizing the role of inclusion as a moderator of the relationship between workplace diversity and organizational outcomes (Nishii, 2013). Simply put, the benefits of workplace diversity cannot be realized without workplace inclusion (Ferdman, 2014). Here, inclusion refers to the degree to which employees perceive themselves as being a valued member of the organization, something that occurs when their needs for belongingness and uniqueness are satisfied (Mor Barak, 2015; Shore et al., 2011). Employee's needs are significantly influenced by behaviors, policies, and practices operating at different levels of the organizational structureincluding intra-personal, inter-personal, and organizationlevel factors (Ferdman, 2014; Mor Barak, 2015). Given its significance for individual and organizational outcomes, understanding the factors fostering workplace inclusion is an important endeavor.

\section{Workplace Experiences of Trans Employees}

Diversity and inclusion research has traditionally focused on socio-demographic traits such as age, sex, and ethnicity/ race (Jackson et al., 2003). More recently, there have been timid attempts to examine workplace inclusion in relation to sexual orientation and gender identity (Day \& Greene, 2008). Despite this, studies on sexual and gender minorities have tended to lump these groups together and/or prioritize sexual orientation, particularly the experiences of gay and lesbian employees (Beauregard et al., 2018). Workplace inclusion amongst trans employees, defined as individuals whose gender identity or expression diverges from their sex assigned at birth, remains poorly understood (Patev et al., 2019). Because trans employees are numerically under-represented and have little voice in the workplace (Beauregard et al., 2018), they are considered a "blind spot" for many organizations (Ozturk $\&$ Tatli, 2016, p.782).

Sexual orientation and gender identity are overlapping yet distinct constructs. While trans employees share their minority status with lesbian, gay, and bisexual (LGB) employees, they also face unique challenges that make their workplace experiences distinctive. Trans individuals may be more visually distinct (Grant et al., 2010) and thus more easily identifiable than LGB employees, and hence more likely to be perceived and/or treated as "different" or as "outsiders." Further, public support for trans individuals and antidiscrimination laws protecting this group are lower than the analogous support and laws toward LGB people (Lewis et al. 2017). As a result, trans employees are more frequent targets of discrimination and bullying in the workplace than individuals with minority sexual orientations (Sawyer et al., 2016). Because trans people are typically a smaller workplace minority than LGB people, their ability to seek and receive support from other in-group members is more limited. In addition, the process of gender transitioning (or gender affirmation), whereby an individual aligns their gender presentation to their gender identity, also poses unique challenges for trans employees (Ozturk \& Tatli, 2016). This process can be highly stressful for trans people, who often meet skepticism or resistance from co-workers and supervisors, and who may require psychological and even medical support (Ozturk \& Tatli, 2016; Pepper \& Lorah, 2008).

McFadden (2015) distinguishes between two types of discrimination: formal discrimination (prejudices manifesting in formalized contexts, such as in job hiring, performance evaluation, or employment termination) and informal discrimination (interpersonal incidents, such as being bullied, ostracized, or harassed). Research on trans employees has largely focused on the former, documenting that these employees are substantially less likely to find employment (Badgett et al., 2007) and get promoted (Grant et al., 2011) and much more likely to quit—or be fired from - their jobs (Budge et al., 2010; Dietert \& Dentice, 2009; Grant et al., 2011). Nonetheless, in-depth interviews with trans employees also reveal the high extent of interpersonal discrimination that they experience. These experiences range from outright physical threats and verbal harassment (Budge et al., 2010; Nadal et al., 2012) to more subtle stressors, such as being the target of malicious gossip, transphobic jokes and remarks, or being ostracized by colleagues (Collins et al., 2015; Dietert \& Dentice, 2009).

\section{Fostering Trans-Inclusive Workplaces: The Role of Language}

While language is often invoked in the context of discrimination, it can also serve as a powerful tool for the workplace inclusion of trans employees (Collins \& Clément, 2012; Diversity Council Australia, 2016; Sawyer et al., 2016). Central to this is the correct use of pronouns to refer to trans employees, binary and non-binary (Zimman, 2017). Although not all trans individuals use pronouns that differ from those corresponding to their sex at birth, many of them choose to do so. For instance, $84 \%$ of the 27,700 respondents in the US Transgender Survey reported using a different set of pronouns than those assigned at birth to refer to themselves (James et al., 2016). The most commonly used pronouns amongst trans individuals (binary and nonbinary) were "he/his" (37\%), "she/her" (37\%), and "they/ their" (29\%). A smaller share used the pronouns "ze/hir" (2\%) or others not identified in the survey (4\%). Importantly, pronouns are highly personal. For instance, not all trans nonbinary individuals choose to use "they," and others may use more than one set of pronouns or no pronouns at all (only first names) (National LGBT Health Alliance, 2013). 
One type of language-related discrimination that is specifically targeted towards trans employees is misgendering. Misgendering refers to "the use of gendered language that does not match how people identify themselves, such as when people who identify as women are described as men" (Ansara \& Hegarty, 2014, p.260). It often involves the use of personal pronouns that do not align with how a trans individual identifies-a practice known as mispronouning (Ansara \& Hegarty, 2014). One example is when a trans woman using the pronoun "she" is addressed by others as " $h e$," either intentionally or unintentionally (Nadal et al., 2012). Mispronouning is a common experience amongst trans employees. Of the nearly 6500 respondents in the 2008 National Transgender Discrimination Survey in the USA, $26 \%$ of trans non-binary respondents and $51 \%$ of trans binary respondents reported having been mispronouned "repeatedly and on purpose" at work (Grant et al., 2011, p.62). These findings are consistent with those from a recent general-population online survey conducted in the USA, UK, Canada, and Australia, where between 12\% (UK) and $22 \%$ (USA) of respondents admitted using incorrect pronouns when addressing trans binary people (Ipsos, 2018).

Qualitative studies focusing on the workplace experiences of trans individuals show that incorrect pronoun use not only creates stress, but also leads to feelings of rejection and invalidation (Budge et al., 2010; Kelly et al., 2020). The few studies exploring the impacts of appropriate pronoun use on trans employees have demonstrated that they help cultivate feelings of inclusion (Hanssmann et al., 2008). Based on interviews with trans employees, Budge and colleagues (2010) concluded that the use of correct pronouns was interpreted by trans individuals as a sign of workplace acceptance. Similarly, Thoroughgood et al. (2020) argued that trans employees attached great importance to simple acts of promoting proper pronoun usage by their co-workers. Taken together, these findings suggest that inclusive language plays a critical role in shaping the workplace experiences of individual trans employees. Critically, cumulative experiences of this type of discrimination may accrue, resulting in profound, detrimental effects on the long-term work careers of trans people (see, e.g., Ozturk \& Tatli, 2018).

Given the importance of inclusive workplace language for the wellbeing of trans individuals and the fact that its use is not uniform, it is important to gain a clearer understanding of the individual- and organizational-level factors that promote and/or inhibit this. In the remainder of the paper, we develop and test different hypotheses about these factors, which constitute our key contribution to the scholarly literature.

\section{Theorizing the Predictors of Trans-Affirming Language Use}

In theorizing potential predictors of inclusive and non-inclusive language use toward trans individuals in the workplace, we adhere to several principles. First, we follow socio-ecological models of workplace relations by recognizing that these predictors may manifest at different levels of the organizational structure (Ferdman, 2014; Mor Barak, 2015). For instance, they may relate to the characteristics of individual employees (e.g., their age or gender), but also to broader workplace conditions (e.g., location or organizational culture). Second, we theorize inclusive and non-inclusive language use as being underpinned by three broad sets of factors: cognitive factors (e.g., awareness of inclusion issues or about the appropriate way to address trans individuals), language factors (e.g., level of English-language proficiency and ability to incorporate new language into one's lexicon), and attitudinal factors (e.g., degree of support for workplace diversity and/or trans people). Third, we focus on individual and organizational traits that are measurable in the data at hand, thereby deriving theoretical propositions that we are able to test empirically.

A first set of factors that may influence an employee's use of inclusive language use towards trans colleagues pertains to the employee's gender identity and sexual orientation. Cisgender heterosexual women as well as individuals from gender and sexual minorities hold more supportive views about sexual and gender diversity than cisgender heterosexual men (Flores, 2015; Grollman, 2017; Perales \& Campbell, 2018). For women, the difference is often attributed to a higher capacity for empathy and a stronger sense of solidarity with disadvantaged groups due to their own experiences of discrimination and oppression (Perales \& Campbell, 2018). For individuals from diverse genders and sexualities, explanations often emphasize their higher investment in fostering inclusive workplace practices. These employees have an enhanced awareness of the value of inclusion and of what constitutes inclusive language and experience more direct personal gains through inclusion (Badgett et al., 2013). For these reasons, we hypothesize that the degree of comfort using trans-affirming language will be greater among female, gender-minority, and LGB employees than that of cisgender, heterosexual men (Hypothesis 1). However, there may also be disparities in the degree of comfort using trans-affirming language across members of different sexual-minority groups. For example, evidence shows that some gay men are highly supportive of cis-normative standards, penalizing gay men who behave or dress in gender non-conforming ways (see, e.g., Ozturk et al., 2020). For this reason, we compare the degree of comfort using trans-affirming language across finely defined sexual- and gender-minority groups.

In addition to gender and sexual expression, we expect other socio-demographic characteristics of employees to be associated with inclusive and non-inclusive language use toward trans individuals in the workplace. Concerning age, we expect younger individuals to be more comfortable using inclusive language than older individuals. This responds to 
evidence of more progressive attitudes toward sexual and gender minorities among individuals born in more recent cohorts (Flores, 2015; Smith et al., 2014), coupled with greater cognitive barriers to expanding one's lexicon associated with ageing (Wright, 2016). We also expect education to be positively related to the use of inclusive language, given its association with increased verbal ability and greater support for civil liberties (Ohlander et al., 2005; Perales, 2018). In contrast, religiosity is likely to have a negative effect on inclusive language use, given widespread disapproval of same-sex behavior and support for traditional gender roles across individuals from different religious denominations (Perales et al., 2019). Finally, individuals from a culturally and linguistically diverse (CALD) background-defined here as Australian residents coming from countries whose main language is not English-may be less likely to use inclusive language. This responds to both evidence of more conservative attitudes toward gender and sexuality in many non-Western cultures (Kite et al., 2019) and possible difficulties in incorporating new terms and complex pronouns in a non-native language. Altogether, we expect that the degree of comfort using trans-affirming language will be greater among younger, more educated, non-religious, and native English-speaking employees (Hypothesis 2). We formulate no explicit prediction for employees being of Aboriginal or Torres Strait Islander (i.e., Indigenous) descent. However, given the significance of this demographic indicator in the Australian context, we include a relevant variable as a model covariate to explore its independent influence.

As noted earlier, broader factors at the organizational or workplace level may also influence the use of trans-inclusive language. Levels of structural stigma against sexual and gender minorities vary across different workplaces and/or organizations based on their physical or sectoral location. For example, stigma may be greater in less urbanized areas (Valfort, 2017) and in more male-dominated industries and/ or sectors of employment (e.g., mining, law enforcement, or construction) (Collins, 2015). As a result, both the awareness of appropriate conventions to address trans individuals and the predisposition to adapt one's language to suit their needs may be lower among employees working in these settings. Given shifting organizational discourses around the importance of diversity and inclusion, we also expect individuals in more senior roles (e.g., managerial and executive positions) to "lead the way" in terms of using inclusive language for trans employees (Cottrill et al., 2014). Altogether, we hypothesize that the degree of comfort using trans-affirming language will be greater amongst employees working in urban areas, certain industries/sectors, and those occupying senior roles (Hypothesis 3). Another plausible influence is the organization's size. On the one hand, smaller firms may provide enhanced opportunities for meaningful inter-personal contact with individuals from gender and sexual minorities (Tee \&
Hegarty, 2006). On the other hand, larger firms tend to have greater resources to allocate to diversity training and awareness and formal channels to combat workplace discrimination and harassment (Day \& Greene, 2008). Given these competing forces, we make no a priori predictions about the relative levels of comfort using trans-appropriate language among employees in smaller and bigger organizations.

Finally, a positive workplace climate cultivated through inclusive policies and practices should encourage organizational citizenship behaviors, including the use of inclusive language (Nishii, 2013; Panicker et al., 2018). This should apply most strongly to organizations that score highly in objective and externally defined markers of workplace diversity and inclusion in the space of gender and sexuality. Thus, our final hypothesis is that the degree of comfort using transaffirming language will be greater among employees in organizations with highly inclusive climates (Hypothesis 4).

\section{The Australian Context}

We study the individual and organizational predictors of trans-inclusive language in the workplace in a relatively progressive country: Australia. Public attitudes toward LGBT issues in Australia have become substantially more supportive in the last few decades (Perales \& Campbell, 2018). In a cross-country survey measuring attitudes toward homosexuality, Australians averaged 6.3 on a scale of 1 (low acceptance) to 10 (high acceptance) over the 2001-2014 period, a substantial increase from an average of 4.2 in the previous two decades (Valfort, 2017). Attitudes toward trans individuals, more specifically, are difficult to gauge due to the scarcity of suitable data (Valfort, 2017). One exception is a 2016 survey conducted by Ipsos and the Williams Institute, where Australia ranked eighth of 23 countries in relation to public support for transgender rights.

Australia has also made significant inroads in improving legal protections for sexual and gender minorities in recent years. In 2013, the Sex Discrimination Act 1984 was amended to explicitly prohibit discrimination on the basis of a person's sexual orientation, gender identity, or intersex status (Australian Human Rights Commission, 2014). The Act encompasses key areas of public life, including employment, education, housing, and the provision of goods and services (Australian Human Rights Commission, 2013). Another important milestone was the legalization of samesex marriage in 2017, which paved the way for couples to marry regardless of sex or gender (Perales \& Campbell, 2018; Riseman, 2019). While Australia's legal protections toward LGB people rank highly in international comparisons (OECD, 2020), Australia lags behind the OECD average in relation to laws protecting gender minorities (OECD, 2020). For example, unlike countries such as France, Germany and the Netherlands, Australia still requires trans binary people 
to undergo medical procedures to change their legal gender (OECD, 2020). This is consistent with Riseman's (2019) observation that trans and intersex rights and acceptance were somewhat slower than LGB rights to enter the Australian public agenda. Indeed, recent Australian evidence points to the existence of significant barriers to inclusion amongst trans people, in the workplace and otherwise (Bates et al., 2020; Jones, 2016; Sullivan, 2018). In the next section, we describe the data and methods that we deploy to examine trans-inclusive language in the workplace within this institutional context.

\section{Data and Methods}

\section{Dataset and Sample}

Pride in Diversity is a program of ACON, Australia's largest not-for-profit Lesbian, Gay, Bisexual, Trans, and Queer (LGBTQ) community health organization. The program was set up to provide employer support for all aspects of LGBTQ workplace inclusion. Since 2011, Pride in Diversity has monitored LGBTQ workplace inclusion policies and practices through its Australian Workplace Equality Index (AWEI). A key component in this task is an annual, repeated cross-sectional, national employee survey aimed at documenting the impact of LGBTQ inclusion initiatives on organizations and their employees: the AWEI Employee Survey (Pride in Diversity, 2019). This study is based on data from the 2020 AWEI Employee Survey, the ninth and largest iteration of the employee survey. This is a voluntary, online survey issued to employees within organizations that either were members of Pride in Diversity or that participated in the benchmarking process as non-members. These organizations encompass a wide range of sectors and industries. A total of 26,700 individuals completed the survey module on inclusive language use. After losing approximately $3 \%$ of cases due to missing data on the covariates, the final analytic sample encompasses 25,776 to 25,815 individuals (depending on the model) from 149 organizations.

The 2020 AWEI Employee Survey collects rich information on topics such as personal beliefs about inclusion, visibility of LGBTQ issues at work, ally behaviors, and workplace experiences. While there are some limitations associated with the online and voluntary nature of the survey (including an over-representation of individuals from gender and sexual minorities), these are far outweighed by the novel insights into processes of workplace inclusion that this unique dataset can offer.As we discuss later, the nature of our analyses makes them less vulnerable to the selection bias typically associated with non-probability samples.

\section{Survey Measures}

We use the AWEI Employee Survey data to derive two outcome variables tapping into different dimensions of language use towards trans employees. The questions ask the full sample of respondents to rate their degree of agreement with the following statements: (1) "I would be comfortable using they/their/them personal pronouns for a non-binary person at work" and (2) "I would be comfortable referring to a colleague by a different name or personal pronouns if they were affirming their gender (transitioning) at work". Responses are in a Likert scale going from [1] "strongly disagree" to [5] "strongly agree." As seen in Table 1, a majority of survey respondents "agree" or "strongly agree" with both propositions, although there is some variation across statements.

The AWEI Employee Survey allows us to derive an encompassing set of variables capturing individual- and employer-level factors that may predict inclusive-language use toward trans employees, and which are used as explanatory variables in our models. These variables align with the theoretical factors discussed before, and fall into four blocks.

Respondents' gender and sexual identity is captured through an exhaustive and mutually exclusive set of eight dummy variables distinguishing between the following categories: cisgender heterosexual man, cisgender heterosexual woman, cisgender non-heterosexual man, cisgender non-heterosexual woman, trans man, trans woman, trans non-binary (assigned male), and trans non-binary (assigned female). We also include an additional dummy variable for individuals who did not provide sufficient information to be classified into these categories.

Respondents' socio-demographic characteristics include the respondent's age (six categories ranging from " $<24$ years" to " $65+$ years"), highest educational attainment (six categories ranging from "primary education" to "postgraduate degree"), and dummy variables $(0=$ No, $1=$ Yes) capturing whether respondents identify as coming from a culturally and linguistically diverse (CALD) background, being Indigenous, and being religious.

Employment-related characteristics include workplace location (urban, regional, rural, remote), industry (24 categories), sector (federal/state/local government, higher education, private, not-for-profit), and organization size (four categories from "small ( $<500$ employees)" to "significant (>8000 employees)," as well as the respondent's position within the organization (senior and executive level, middle management, regular employee).

Workplace environment is approximated through the use of the 2020 Australian Workplace Equality Index (the Index), a composite measure capturing the quality of an organization's LGBTQ-inclusion policies and practices. The Index is constructed by adding up scores on separate 
Table 1 Summary statistics

\begin{tabular}{|c|c|}
\hline Variables & $n(\%)$ \\
\hline \multicolumn{2}{|c|}{ Comfortable using they/their/them pronouns for non-binary person } \\
\hline Strongly disagree & $1194(4.5 \%)$ \\
\hline Disagree & $1569(5.9 \%)$ \\
\hline Neither agree nor disagree & $2996(11.2 \%)$ \\
\hline Agree & $7106(26.6 \%)$ \\
\hline Strongly agree & $13,846(51.8 \%)$ \\
\hline \multicolumn{2}{|c|}{ Comfortable using different name or personal pronouns after transitioning } \\
\hline Strongly disagree & $690(2.6 \%)$ \\
\hline Disagree & $827(3.1 \%)$ \\
\hline Neither agree nor disagree & $2008(7.5 \%)$ \\
\hline Agree & $7254(27.1 \%)$ \\
\hline Strongly agree & $15,970(59.7 \%)$ \\
\hline \multicolumn{2}{|l|}{ Sexual orientation and gender diversity } \\
\hline Cisgender heterosexual man & $8312(31.0 \%)$ \\
\hline Cisgender heterosexual woman & $12,257(45.8 \%)$ \\
\hline Cisgender non-heterosexual man & $2606(9.7 \%)$ \\
\hline Cisgender non-heterosexual woman & $2238(8.4 \%)$ \\
\hline Trans man & $90(0.3 \%)$ \\
\hline Trans woman & $114(0.4 \%)$ \\
\hline Trans non-binary (assigned male at birth) & $73(0.3 \%)$ \\
\hline Trans non-binary (assigned female at birth) & $139(0.5 \%)$ \\
\hline Insufficient information to classify & $960(3.6 \%)$ \\
\hline \multicolumn{2}{|l|}{ Age group } \\
\hline$<24$ years & $1389(5.2 \%)$ \\
\hline $25-34$ years & $7081(27.2 \%)$ \\
\hline $35-44$ years & $7745(28.9 \%)$ \\
\hline $45-54$ years & $6808(25.4 \%)$ \\
\hline $55-64$ years & $3255(12.2 \%)$ \\
\hline $65+$ years & $258(1.0 \%)$ \\
\hline Prefer not to say & $253(0.9 \%)$ \\
\hline \multicolumn{2}{|l|}{ Respondent identifies as Indigenous } \\
\hline No & $25,189(97.4 \%)$ \\
\hline Yes & $664(2.6 \%)$ \\
\hline \multicolumn{2}{|c|}{ Respondent identifies as having a CALD background } \\
\hline No & $23,064(89.2 \%)$ \\
\hline Yes & $2789(10.8 \%)$ \\
\hline \multicolumn{2}{|l|}{ Respondent identifies as religious } \\
\hline No & $22,024(85.2 \%)$ \\
\hline Yes & $3829(14.8 \%)$ \\
\hline \multicolumn{2}{|l|}{ Highest educational attainment } \\
\hline Primary education & $91(0.3 \%)$ \\
\hline Secondary education & $2745(10.2 \%)$ \\
\hline Certificate or diploma & $6055(22.6 \%)$ \\
\hline Bachelor degree, or equivalent & $11,573(43.2 \%)$ \\
\hline Postgraduate degree & $6121(22.8 \%)$ \\
\hline Other & $204(0.8 \%)$ \\
\hline \multicolumn{2}{|l|}{ Remoteness of work location } \\
\hline Urban area & $22,751(84.9 \%)$ \\
\hline Regional area & $3117(11.6 \%)$ \\
\hline Rural area & $534(2.0 \%)$ \\
\hline Remote area & $387(1.4 \%)$ \\
\hline
\end{tabular}


Table 1 (continued)

\begin{tabular}{|c|c|}
\hline Variables & $n(\%)$ \\
\hline \multicolumn{2}{|l|}{ Position in organization } \\
\hline Senior and executive level & $3166(11.8 \%)$ \\
\hline Middle management & $3459(12.9 \%)$ \\
\hline Regular employee & $20,164(75.3 \%)$ \\
\hline \multicolumn{2}{|l|}{ Organizational size } \\
\hline Small (<500 employees) & $1382(5.7 \%)$ \\
\hline Medium (501-1999 employees) & $3432(14.5 \%)$ \\
\hline Large (2000-8000 employees) & $10,600(46.4 \%)$ \\
\hline Significant (> 8000 employees) & $7413(33.4 \%)$ \\
\hline No data & $3962(14.8 \%)$ \\
\hline \multicolumn{2}{|l|}{ Industry of employment } \\
\hline Aged care & $144(0.5 \%)$ \\
\hline Banking and financial services & $2421(9.0 \%)$ \\
\hline Community services & $750(2.8 \%)$ \\
\hline Construction & $292(1.1 \%)$ \\
\hline Education & $2459(9.2 \%)$ \\
\hline Energy and utilities & $1531(5.7 \%)$ \\
\hline Health and wellbeing & $220(0.8 \%)$ \\
\hline Hospitality & $907(3.4 \%)$ \\
\hline Insurance & $1258(4.7 \%)$ \\
\hline Law enforcement & $2737(10.2 \%)$ \\
\hline Legal & $1506(5.6 \%)$ \\
\hline Media and entertainment & $454(1.7 \%)$ \\
\hline Mining & $1105(4.1 \%)$ \\
\hline Pharmaceuticals & $318(1.2 \%)$ \\
\hline Professional services and consulting & $1768(6.6 \%)$ \\
\hline Property & $368(1.4 \%)$ \\
\hline Public service & $5817(21.7 \%)$ \\
\hline Rail and logistics & $114(0.4 \%)$ \\
\hline Recruitment & $132(0.5 \%)$ \\
\hline Research and development & $241(0.9 \%)$ \\
\hline Retail & $1102(4.1 \%)$ \\
\hline Technology and telecommunications & $729(2.7 \%)$ \\
\hline Tourism and gaming & $60(0.2 \%)$ \\
\hline Transport & $356(1.3 \%)$ \\
\hline \multicolumn{2}{|l|}{ Sector of work } \\
\hline Government & $10,884(40.6 \%)$ \\
\hline Private sector & $12,920(48.2 \%)$ \\
\hline Higher education & $2433(9.1 \%)$ \\
\hline Not-for-profit & $552(2.1 \%)$ \\
\hline \multicolumn{2}{|l|}{ Inclusion Index quartile } \\
\hline Q1 & $2347(8.8 \%)$ \\
\hline Q2 & $5809(21.7 \%)$ \\
\hline Q3 & $8021(29.9 \%)$ \\
\hline Q4 & $6650(24.8 \%)$ \\
\hline No data & $3962(14.8 \%)$ \\
\hline
\end{tabular}

Australian Workplace Equality Index Employee Survey 2020 data

$C A L D$ culturally and linguistically diverse 
dimensions, such as human-resource policies, diversity practices, employee networks, training and professional development, and community engagement—for details, see Pride in Diversity (2019). To make the Index comparable between small and standard employers (which are subjected to different scoring mechanisms), we collapse the raw scores into quartiles. Organizations in the top quartile (Q4) have the most inclusive LGBTQ policies relative to other participating organizations. ${ }^{1}$

Descriptive statistics on all explanatory variables are presented in Table 1.

\section{Analytic Approach}

To examine the associations between the explanatory variables and each of the ordered outcome variables capturing respondents' comfort using trans-affirming language, we estimate two ordered logistic regression models-one for each outcome. To ease interpretation, the model coefficients on the explanatory variables are exponentiated and thus expressed as odds ratios (ORs). The ORs give the probability of being in a higher (compared to an equal or lower) level of the ordered outcome variable associated with a one-unit increase in a given explanatory variable, controlling for all other variables in the model. ORs greater than one denote positive associations with inclusive language use, whereas ORs smaller than one denote negative associations.

\section{Empirical Evidence}

\section{Main Analyses}

The results from our multivariable ordered logistic regression models are presented in Table 2. Columns 1 to 3 show the results for the model pertaining to the degree of comfort using they pronouns to refer to a trans non-binary person at work, whereas columns 4 to 6 show the results for the model pertaining to the degree of comfort using different names and pronouns for a colleague undergoing a gender transition.

\section{Gender and Sexual Identity}

In both models, respondents who identify as cisgender heterosexual men (the reference category) were significantly less likely to be comfortable using trans-inclusive language at work than all other groups, all else being equal. This can

\footnotetext{
${ }^{1}$ Because information on employer size and Index scores is only available for organizations that participate in Pride in Diversity's benchmarking process, we use dummy variables to flag cases with missing data on those variables.
}

be inferred from the fact that the ORs for all of the gender/ sexuality categories in the model were greater than one and statistically significant. Women were more likely to be comfortable using trans-inclusive language than men in the cisgender heterosexual, cisgender non-heterosexual, and trans groups. This is evidenced by larger ORs among women than men, with such differences being statistically significant in Wald tests. ${ }^{2}$ In both models, trans women were the most likely to be comfortable using trans-inclusive language in the workplace, followed by trans non-binary individuals. The magnitude of these associations was substantial, as can be grasped from the average marginal effects presented in columns 3 and 6 . For example, the probability of falling into the strongly agree category of the outcome variable was $55.2 \%$ (model 1) and 50.8\% (model 2) higher for trans women than for cisgender heterosexual men. Overall, these results are highly consistent with Hypothesis 1, which posited that women and individuals from gender/sexual minorities would be more likely to use trans-affirming language than cisgender heterosexual men.

\section{Socio-demographic Characteristics}

The results for the socio-demographic variables also offer empirical insights that align largely with our theoretical predictions. Consistent with Hypothesis 2, age was negatively and linearly related to comfort using trans-affirming language in both models. For example, the odds of expressing higher levels of comfort using they pronouns among employees aged $65+$ years were 0.374 times $(p<0.01)$ those of employees aged 24 years and younger-which translates into a $22.6 \%$ lower probability of falling into the strongly agree category. Similarly, religious individuals were substantially less comfortable with inclusive language than their nonreligious peers, all else being equal. For instance, the odds of expressing higher levels of comfort using a new name and pronouns for a colleague who transitioned decreased by a factor of $0.435(p<0.01)$ among religious compared to non-religious employees. This equates to a $17.4 \%$ lower probability of selecting the strongly agree response option. We also observed a clear positive gradient in trans-affirming use by employees' level of education, ceteris paribus. As an example, individuals with a bachelor degree exhibited significantly higher levels of comfort than individuals with secondary education using they pronouns $(\mathrm{OR}=1.221, p<0.01)$ and using the correct name and pronouns for colleagues who

\footnotetext{
${ }^{2}$ Concerning comfort using they pronouns, Wald tests showed statistically significant differences between cisgender heterosexual men and women $\left(\chi^{2}(1)=1056.10, p<0.001\right)$, cisgender non-heterosexual men and women $\left(\chi^{2}(1)=151.93, p<0.001\right)$, and trans men and women $\left(\chi^{2}(1)=16.09, p<0.001\right)$. The same pattern of results emerged in the model for using different pronouns for trans colleagues.
} 
Table 2 Odds ratios from ordered logistic regression models of trans-inclusive language use

\begin{tabular}{|c|c|c|c|c|c|c|}
\hline \multirow[t]{3}{*}{ Variables } & \multicolumn{3}{|c|}{$\begin{array}{l}\text { Comfortable using they/their/them } \\
\text { pronouns for non-binary person }\end{array}$} & \multicolumn{3}{|c|}{$\begin{array}{l}\text { Comfortable using different names or pronouns } \\
\text { for colleague who transitioned }\end{array}$} \\
\hline & (1) & $(2)$ & (3) & (4) & $(5)$ & $(6)$ \\
\hline & Odds ratio & Standard error & AME & Odds ratio & Standard error & AME \\
\hline \multicolumn{7}{|c|}{ Sexual orientation and gender diversity group (reference: Cisgender heterosexual man) } \\
\hline Cisgender heterosexual woman & $2.495^{* * * *}$ & 0.070 & 0.208 & $2.816^{* * *}$ & 0.083 & 0.234 \\
\hline Cisgender non-heterosexual man & $3.493^{* * *}$ & 0.168 & 0.283 & $4.374^{* * *}$ & 0.232 & 0.321 \\
\hline Cisgender non-heterosexual woman & $8.359^{* * *}$ & 0.512 & 0.447 & $9.642^{* * *}$ & 0.671 & 0.440 \\
\hline Trans man & $3.625^{* * *}$ & 0.895 & 0.291 & $2.778^{* * *}$ & 0.691 & 0.231 \\
\hline Trans woman & $20.276^{* * *}$ & 7.154 & 0.552 & $19.647^{* * *}$ & 7.759 & 0.508 \\
\hline Trans non-binary (assigned male at birth) & $13.501^{* * * *}$ & 5.243 & 0.511 & $7.871^{* * *}$ & 2.890 & 0.415 \\
\hline Trans non-binary (assigned female at birth) & $15.587^{* * *}$ & 4.982 & 0.527 & $12.528^{* * *}$ & 4.183 & 0.469 \\
\hline \multicolumn{7}{|c|}{ Age group (reference: $\leq 24$ years) } \\
\hline $25-34$ years & $0.795^{* * *}$ & 0.061 & -0.031 & $0.845^{* *}$ & 0.061 & -0.031 \\
\hline $35-44$ years & $0.555^{* * *}$ & 0.043 & -0.100 & $0.596^{* * *}$ & 0.043 & -0.100 \\
\hline $45-54$ years & $0.450^{* * *}$ & 0.033 & -0.155 & $0.458^{* * *}$ & 0.033 & -0.155 \\
\hline $55-64$ years & $0.396^{* * *}$ & 0.030 & -0.187 & $0.394^{* * *}$ & 0.030 & -0.187 \\
\hline $65+$ years & $0.374^{* * *}$ & 0.046 & -0.226 & $0.328^{* * *}$ & 0.046 & -0.226 \\
\hline Respondent identifies as Indigenous & 0.907 & 0.073 & -0.021 & 0.905 & 0.077 & -0.020 \\
\hline Respondent identifies as CALD & 1.011 & 0.041 & 0.002 & 0.994 & 0.043 & -0.001 \\
\hline Respondent identifies as religious & $0.472^{* * *}$ & 0.016 & -0.159 & $0.435^{* * *}$ & 0.015 & -0.174 \\
\hline \multicolumn{7}{|c|}{ Educational attainment (reference: Secondary education) } \\
\hline Primary education & 0.861 & 0.188 & -0.032 & 0.774 & 0.179 & -0.053 \\
\hline Certificate or diploma & 0.998 & 0.046 & -0.000 & 0.983 & 0.047 & -0.003 \\
\hline Bachelor degree, or equivalent & $1.221^{* * *}$ & 0.053 & 0.042 & $1.127^{* * *}$ & 0.052 & 0.024 \\
\hline Postgraduate degree & $1.373^{* * *}$ & 0.067 & 0.067 & $1.233^{* * *}$ & 0.063 & 0.042 \\
\hline \multicolumn{7}{|c|}{ Remoteness of work (reference: Urban area) } \\
\hline Regional area & $0.872^{* * *}$ & 0.035 & -0.029 & $0.893^{* * *}$ & 0.037 & -0.023 \\
\hline Rural area & $0.830^{* *}$ & 0.073 & -0.040 & $0.800^{* *}$ & 0.072 & -0.045 \\
\hline Remote area & $0.597^{* * *}$ & 0.061 & -0.108 & $0.648^{* * *}$ & 0.069 & -0.089 \\
\hline \multicolumn{7}{|c|}{ Position in organization (reference: Senior and executive level) } \\
\hline Middle management & $0.830^{* * *}$ & 0.041 & -0.039 & $0.780^{* * *}$ & 0.042 & -0.047 \\
\hline Regular employee & $0.681^{* * *}$ & 0.028 & -0.080 & $0.614^{* * *}$ & 0.027 & -0.095 \\
\hline \multicolumn{7}{|c|}{ Industry of employment (reference: Public service) } \\
\hline Aged care & 1.106 & 0.192 & 0.022 & 0.995 & 0.182 & -0.001 \\
\hline Banking and financial services & 0.920 & 0.048 & -0.018 & 0.923 & 0.052 & -0.016 \\
\hline Community services & $1.269^{* * *}$ & 0.108 & 0.051 & $1.430^{* * *}$ & 0.131 & 0.071 \\
\hline Construction & 0.931 & 0.119 & -0.015 & 0.986 & 0.133 & -0.003 \\
\hline Education & $1.338^{* * *}$ & 0.073 & 0.062 & $1.509^{* * *}$ & 0.089 & 0.081 \\
\hline Energy and utilities & 1.108 & 0.070 & 0.022 & $1.242^{* * *}$ & 0.082 & 0.043 \\
\hline Health and wellbeing & $0.686^{* * *}$ & 0.100 & -0.081 & $0.711^{* *}$ & 0.108 & -0.071 \\
\hline Hospitality & 0.964 & 0.070 & -0.008 & 0.906 & 0.069 & -0.020 \\
\hline Insurance & 1.075 & 0.070 & 0.015 & $1.124^{*}$ & 0.078 & 0.024 \\
\hline Law enforcement & $0.454^{* * *}$ & 0.024 & -0.167 & $0.544^{* * *}$ & 0.029 & -0.127 \\
\hline Legal & 0.915 & 0.063 & -0.019 & 0.993 & 0.073 & -0.002 \\
\hline Media and entertainment & 1.070 & 0.115 & 0.015 & $1.283^{* *}$ & 0.147 & 0.050 \\
\hline Mining & 0.891 & 0.063 & -0.025 & $0.857^{* *}$ & 0.064 & -0.032 \\
\hline Pharmaceuticals & $0.809^{*}$ & 0.094 & -0.045 & 0.839 & 0.102 & -0.036 \\
\hline Professional services and consulting & 0.968 & 0.056 & -0.007 & 1.007 & 0.063 & 0.001 \\
\hline Property & $0.735^{* * *}$ & 0.082 & -0.066 & $0.740^{* *}$ & 0.087 & -0.062 \\
\hline
\end{tabular}


Table 2 (continued)

\begin{tabular}{|c|c|c|c|c|c|c|}
\hline \multirow[t]{3}{*}{ Variables } & \multicolumn{3}{|c|}{$\begin{array}{l}\text { Comfortable using they/their/them } \\
\text { pronouns for non-binary person }\end{array}$} & \multicolumn{3}{|c|}{$\begin{array}{l}\text { Comfortable using different names or pronouns } \\
\text { for colleague who transitioned }\end{array}$} \\
\hline & (1) & (2) & (3) & (4) & (5) & (6) \\
\hline & Odds ratio & Standard error & AME & Odds ratio & Standard error & AME \\
\hline Rail and logistics & 1.008 & 0.197 & 0.002 & 0.918 & 0.187 & -0.017 \\
\hline Recruitment & $0.476^{* * *}$ & 0.088 & -0.157 & $0.476^{* * *}$ & 0.092 & -0.155 \\
\hline Research and development & $1.650^{* * *}$ & 0.244 & 0.105 & $1.870^{* * *}$ & 0.304 & 0.120 \\
\hline Retail & 1.043 & 0.073 & 0.009 & $1.151^{*}$ & 0.087 & 0.028 \\
\hline Technology and telecommunications & $1.360^{* * *}$ & 0.117 & 0.065 & $1.569^{* * *}$ & 0.148 & 0.088 \\
\hline Tourism and gaming & 1.288 & 0.383 & 0.054 & 1.564 & 0.497 & 0.088 \\
\hline Transport & 0.924 & 0.109 & -0.017 & 1.155 & 0.145 & 0.029 \\
\hline \multicolumn{7}{|c|}{ Organizational size (reference: Small (<500 employees)) } \\
\hline Medium $(501-1,999)$ & 0.908 & 0.066 & -0.020 & 0.899 & 0.070 & -0.020 \\
\hline Large (2000-8000) & $0.709^{* * *}$ & 0.049 & -0.072 & $0.707^{* * *}$ & 0.052 & -0.068 \\
\hline Significant $(>8000)$ & $0.664^{* * *}$ & 0.050 & -0.086 & $0.710^{* * *}$ & 0.057 & -0.067 \\
\hline \multicolumn{7}{|l|}{ Inclusion Index quartile (reference: Q1) } \\
\hline Q2 & 1.051 & 0.060 & 0.010 & 1.006 & 0.061 & 0.001 \\
\hline Q3 & $1.215^{* * *}$ & 0.071 & 0.041 & $1.129^{*}$ & 0.070 & 0.024 \\
\hline Q4 & $1.233^{* * * *}$ & 0.073 & 0.044 & $1.181^{* * *}$ & 0.074 & 0.033 \\
\hline $\mathrm{n}$ & 25,776 & & & 25,815 & & \\
\hline Pseudo $\mathrm{R}^{2}$ & 0.081 & & & 0.096 & & \\
\hline
\end{tabular}

Australian Workplace Equality Index Employee Survey 2020 data. Results for "Prefer not to say," "Others," and missing data categories omitted $A M E$ average marginal effects for the "Strongly agree" category, $C A L D$ culturally and linguistically diverse

Statistical significance: $* p<0.10 ; * * p<0.05 ; * * p<0.01$

transitioned ( $\mathrm{OR}=1.127, p<0.01)$. In contrast, against the predictions in Hypothesis 2, we found no statistically significant differences in the degree of (dis)comfort concerning trans-affirming language use between employees with and without a CALD background. Neither were there differences by Indigenous identification.

\section{Employment-Related Factors}

Our theoretical framework also led us to expect certain employment-related characteristics to be associated with the use of trans-affirming language at work (Hypothesis 3). Consistent with these hypotheses, the models showed that the distance from urban areas is inversely related to comfort using trans-affirming language. For instance, compared to the reference category of "urban area," the ORs for the category "remote area" were 0.597 in model $1(p<0.01)$ and 0.648 in model $2(p<0.01)$. In the metric of predicted probabilities, these ORs equate to decreases in the probability of strongly agreeing with the statements presented of $10.8 \%$ and $8.9 \%$, respectively. Also consistent with expectations, employees who hold more senior positions within the organization expressed greater comfort using inclusive language toward their trans peers than other employees, all else being equal. As an example, the odds of reporting higher levels of comfort using they pronouns among regular employees decreased by a factor of $0.681(p<0.01)$ compared to senior leaders-or an $8 \%$ decrease in the probability of selecting the strongly agree response option. The results further revealed significant heterogeneity in inclusive-language use across industry sectors, with remarkable consistency across both models in the sectors that performed better (e.g., education, community services, and research and development) and those that performed worse (e.g., recruitment, health and wellbeing, property, and law enforcement).

While we made no explicit predictions concerning employer size, we found that employees in the smallest organizations exhibited the greatest adjusted levels of comfort using transinclusive language. For instance, the odds of individuals being comfortable using the correct name and pronouns of trans colleagues in organizations with $8000+$ employees were 0.710 times $(p<0.01)$ those of employees in organizations with less than 500 employees. This is equivalent to a $6.7 \%$ decrease in the probability of strongly agreeing with the statement.

\section{Organizational Climate}

As posited in Hypothesis 4, we found that employees in those companies who scored highly on the inclusion Index exhibited greater levels of trans-affirming language use, 
ceteris paribus. For example, organizations in the top quartile of the Index had ORs that were 1.233 times (model 1) and 1.181 times (model 2) greater than those of organizations in the lowest Index quartile ( $p<0.001$ in both cases). That is, individuals in the most inclusive organizations had a 3.3 to $4.4 \%$ lower probability of selecting the strongly agree category, all else being equal.

Despite strong evidence of significant factors associated with inclusive language use in both models, our variables collectively explained approximately $8-9 \%$ of the variance in the outcomes of interest (as denoted by the pseudo- $R^{2}$ values). This pattern of results serves to underscore the diversity of observed and unobserved factors that contribute to individuals' embracing inclusive workplace language.

\section{Sensitivity and Additional Analyses}

To ascertain the robustness of our findings to different analytic decisions, we implemented a range of sensitivity analyses and specification checks, with reassuring results (see Tables A1 to A3 in the Online Supplementary Materials). First, we confirmed that the pattern of results was similar when we treated our ordered outcome variables as cardinal variables within a linear model (Column 2, Tables A1 and A2). Second, we examined whether results changed when implementing more complex multilevel models where individuals (Level 1) are nested within organizations (Level 2). The patterns of association were highly consistent to that in our main analyses in models treating organization-level heterogeneity as a random effect (column 3) and as a fixed effect (column 4). ${ }^{3}$ Third, it could be argued that the inclusion Index taps into some of the mechanisms that may connect other organizational characteristics to employees' levels of comfort using transaffirming language. This could lead to downward-biased estimates on the organizational characteristics. For this reason, we replicated our main models excluding the Index (column 5). Reassuringly, the estimated model coefficients on the organizational characteristics remained similar. Fourth, since employment sectors overlap to a large extent with industry sectors, we fitted separate models including the former instead of the latter. The results of these alternative specifications are presented in Table A3 and reveal theoretically meaningful differences in inclusive-language use across employment sectors. All else being equal, employees in the not-for-profit sector expressed the greatest levels of comfort using inclusive language across both models, followed by those in the highereducation sector, those in the private sector, and, finally,

\footnotetext{
${ }^{3}$ In fact, inspection of the intra-class correlations revealed that organization-level factors explained only 4.22 to $4.87 \%$ of the total variance in the outcome variables in linear random-effect models with no predictors, and 0.33 to $0.34 \%$ of the unobserved variance in fully specified linear random-effect models.
}

those in the public sector. Finally, we examined whether the industrial differences observed had their roots in a culture of hegemonic masculinity. We accomplished this by replacing the original set of industry dummy variables with a continuous-level variable capturing the percentage of AWEI Survey respondents who identified as cis-gender heterosexual men in the respondents' industry of work. A greater percentage of cis-gender heterosexual men in the industry were associated with lower odds of an employee being comfortable using trans-affirming language-irrespective of the employee's own gender or sexuality (Table A3). This suggests that a culture of hegemonic masculinity is partially responsible for industrial disparities in use of trans-affirming language.

\section{Discussion and Conclusion}

Despite strong evidence indicating that trans individuals occupy disadvantaged positions within the labor market, we know very little about the factors that facilitate their workplace inclusion. In this study, we have contributed to filling this gap in knowledge by theorizing and empirically examining processes of workplace inclusion among trans individuals, with a focus on the underexplored domain of language. Through innovative use of a large-scale, linked employer-employee dataset and multivariable statistical modelling, we were able to generate unique insights into the individual- and employer-level factors associated with the use of trans-affirming language in Australian workplaces.

Consistent with our first hypothesis, employees' own gender and sexuality were powerful predictors of their language practices toward trans colleagues. Specifically, we found that women and people from gender and sexual minorities were more comfortable using inclusive language when addressing their trans peers than cisgender heterosexual men. As discussed before, the magnitude of these associations was fairly substantial. These results may reflect a greater degree of awareness about inclusive language among trans people themselves (see Zimman, 2017), as well as among individuals from sexual minorities. They also indicate that as previously reported for attitudes toward same-sex relations (Perales \& Campbell, 2018) and overall use of inclusive language (Patev et al., 2019)—cisgender heterosexual men also lag behind in the adoption of inclusive language practices toward trans colleagues. Interestingly, cis-gender non-heterosexual men were less comfortable using trans-affirming language than individuals from most other groups. This finding is consistent with earlier studies documenting differences in support for hegemonic masculinity across sexual- and gender-minority groups (see, e.g., Ozturk et al., 2020), and underscores the importance of considering "diversity within diversity" when examining individuals' support for gender (non-)traditional practices. 
Our second hypothesis pertained to other socio-demographic traits of employees, besides their gender and sexual identity. Consistent with expectations, we observed higher levels of comfort using trans-affirming language amongst younger, more educated, and non-religious employees - with moderate effect sizes. These associations resemble those reported by previous studies examining socio-demographic correlates of attitudes toward LGBTQ issues (Perales \& Campbell, 2018). Contrary to our expectations and to this literature, however, we found no differences between CALD employees and other employees. Neither did we find differences between Indigenous and non-Indigenous employees. This pattern of results suggests that ethno-migrant background is not an important factor in structuring the use of inclusive language in relation to trans issues within Australian workplaces. It is possible that many CALD and Indigenous employees are more acutely aware of inclusion issues due to their own minority identities, but also that this is offset by some subgroups within these umbrella categories holding traditional values about gender and sexuality. Further, people from CALD backgrounds who are native speakers of languages that accommodate gendered and nongendered pronouns to various degrees may differ in the ability to adopt they pronouns when speaking English. Either way, our findings point to the importance of future research exploring inter-group heterogeneity.

Following multilevel approaches to conceptualizing workplace inclusion, we hypothesized that certain employerrelated characteristics would foster or inhibit the use of trans-affirming language-net of differences in employees' socio-demographic traits. Our analyses yielded support for this hypothesis, indicating that factors such as employer's location, industry, and sector were all important determinants of inclusive language use. Specifically, better practices were observed in urban, not-for-profit, and higher-education employers compared to regional, rural, private-sector, and public-sector employers. None of these associations came as a surprise, as they resemble patterns that have been identified between the same employer-related factors and other markers of workplace inclusion-such as rates of harassment or discrimination (Brolis et al., 2018; Saunders \& Easteal, 2013).

The industrial and sectoral differences observed are important and, in some cases, a cause for concern. Employees in the public sector and those in certain industries aimed at safeguarding and enhancing people's welfare (e.g., health and wellbeing, law enforcement, and recruitment) were significantly less likely to be comfortable using trans-affirming language. The fact that employees in the health and wellbeing sector were among the least inclusive resonates with literature documenting challenges in accessing healthcare for individuals from diverse genders and sexualities (Puckett et al., 2018). These individuals often report postponing or avoiding treatment due to a fear of being stigmatized or discriminated against (Grant et al., 2010; Puckett et al., 2018), and noninclusive language is recurrently cited as an instance of these experiences (Goldberg et al., 2019). The results regarding employees in law enforcement and recruitment echo those of previous studies showing that trans individuals routinely experience discrimination from the police and during the hiring process (Grant et al., 2011). Apart from reinforcing stigma against trans employees, these patterns may also harm organizations indirectly by reducing their effectiveness and restricting their capacity to attract talent (Mallory et al., 2015; Badgett et al., 2013).

Individuals' positions within the organization were also important, with more senior employees "leading the way" in the use of trans-inclusive language. This finding underscores the significant role that managers, supervisors, and senior executives can play as innovators in the space of workplace inclusion, through leadership and role modeling (Boekhorst, 2014; Mor Barak, 2015). Our results also revealed that employees in firms that had attained higher scores in an Index of diversity and inclusion practices in the workplace were more likely to use inclusive language. This finding was consistent with our fourth and final hypothesis and speaks to the importance of cultivating workplace environments that promote understanding and respect of the needs of employees with diverse genders and sexualities. While we did not have a priori expectations about firm size, our empirical results suggested that trans-affirming language was more prevalent in smaller rather than larger firms. This finding aligns with perspectives emphasizing greater flexibility to encourage behavioral change within smaller firms (Richard et al., 2013) and that these firms provide greater opportunities for meaningful interpersonal contact, which can in turn help overcome stereotypes and stigma (Pettigrew \& Tropp, 2006). It also aligns with previous research findings indicating that small firms benefit the most from inclusive workplace practices (Sels et al., 2006).

In relation to theory, our findings confirm the usefulness of theoretical frameworks that conceptualize workplace inclusion as a multilevel process, recognizing the significant contributions made by both individual- and employer-level factors. Research that considers only either set of processes is likely to offer only a partial picture of the factors motivating inclusive language use within the workplace. However, despite the richness of the data and high number of covariates, our models explained only a modest amount of the variance in language use among employees (approximately one tenth). This underscores the multifaceted and complex nature of workplace inclusion processes, including those pertaining to language. It also suggests that future studies should consider additional factors not measured here as plausible drivers of such processes. Based on previous research, putative candidates may include employees' personality traits, cognitive styles and frequency of contact 
with trans people at the individual level, and organization's staffing profiles and presence or visibility of trans people at the aggregate level. The examination of cross-level interactions between socio-demographic factors and employer-level characteristics also constitutes a potentially fruitful way to expand the explanatory power of the models presented here.

Despite the novel insights and important contributions of this study, a noteworthy caveat of the AWEI Employee Survey is that, like other opt-in online surveys, it is prone to selection issues. First, the potential covered population (i.e., all employees of participating organizations) may not be fully representative of the target population (i.e., all employees in Australia). This could result in under-coverage bias (Valliant \& Dever, 2011). Second, the realized sample (i.e., all respondents) may not be fully representative of the potential covered population and/or the target population (Valliant $\&$ Dever, 2011). In relation to this, the non-probabilistic nature of the sample means that the use of inferential statistics is contingent on several untestable assumptions. Nevertheless, selection bias is likely to be comparatively small for our purposes. This is because results from nonprobability surveys are less likely to be biased when analyses focus on relationships between variables rather than on point estimates (Pasek, 2016). In addition, there is growing recognition that surveys need to be evaluated not only on their statistical features, but also on their "fitness for use" (Baker et al., 2013, p.98). In this regard, use of the AWEI Employee Survey is fully justified by its incorporation of unique information that is currently unavailable in population-based survey in Australia-and rarely available internationally. A second, more minor, limitation is that our outcome variables measured employees' comfort using trans-inclusive language, rather than their actual use. Nevertheless, we expect these two constructs to be strongly correlated.

Despite these limitations, our findings yield important lessons for workplace inclusion policies. At a broad level, the results underscore the need to address not just formal types of discrimination against trans employees, but also informal forms occurring at the interpersonal level. However, they also highlight the value of moving beyond "blanket approaches" to providing inclusive workplace climates for different groups of workers (Ozturk \& Tatli, 2016, p.797). Instead, organizational policies and practices need to be tailored to suit the specific needs and unique experiences of trans workers-including the use of trans-affirming language. This is a crucial endeavor, as cumulative experiences of informal discrimination can have profound, negative effects on trans people's employment trajectories (Ozturk \& Tatli, 2018).

Further, the present study confirms the existence of barriers to the use of trans-inclusive language that are unevenly distributed across employee and employer "types" (Kelly et al., 2020; Patev et al., 2019). To the extent that socio-demographic characteristics reflect attitudinal, cognitive, or language-related barriers, efforts need to be directed toward educating employees concerning the appropriate use of names and pronouns when addressing their trans colleagues (Sawyer et al., 2016). In this regard, our findings are invaluable in qualifying which employees and which employers are more likely to require training and support in adopting trans-affirming language, paving the way for more targeted and efficient interventions. Specifically, training programs that manage to engage cisgender heterosexual men; older, less educated, and religious employees; and workers in nonmanagerial roles have a greater chance to make a genuine difference. Similarly, training needs seem particularly acute in large firms; employers without a strong track record of overall inclusion practice; public- and private-sector employers; and organizations within certain industries (e.g., recruitment, health and wellbeing, and law enforcement).

Finally, our study reaffirms the importance of organizational policies and practices aimed at fostering an inclusive environment for trans employees. Specifically, organizations should adopt policies that facilitate appropriate language use toward trans employees affirming their gender identity, including the recognition of new names and pronouns through informal channels and in formal document and communications (Sawyer et al., 2016). Examples of positive practices include - but are not limited to-incorporation of non-binary options when asking about employees' gender, enabling employees to self-select their personal pronouns within human-resource systems, and ensuring congruence in salutation fields on forms.

Our findings also point to important avenues for further research. First, our theoretical model linked socio-demographic and employer-level characteristics to trans-affirming language through cognitive, language, and attitudinal factors. However, we were unable to explicitly capture these factors in our empirical models and doing so would enable the refinement of interventions aimed at fostering inclusive language in the workplace. Qualitative research is perhaps best placed to identify the precise nature of the mechanisms (both barriers and facilitators) implicated in these processes-for example, through in-depth interviews or focus groups with employees whose comfort levels using trans-inclusive language are distinctively high and low. Second, the field would benefit from new studies that undertake similar analyses to those presented here in different country contexts. As described before, Australia represents a relatively supportive institutional environment for individuals with diverse genders and sexualities. Identifying whether or not our findings hold in less supportive (e.g., the USA) or more supportive (e.g., the Netherlands) countries, and the macro-level factors that may moderate the relationships of interest, represent important pathways for further inquiry.

To conclude, while use of appropriate language toward individuals with diverse genders and sexualities constitutes 
an important stepping stone to their workplace inclusion, this study has demonstrated that its adoption remains incomplete and highly segmented. Greater efforts should be directed at understanding what drives inclusive language use across workplaces, and at devising policies and programs that encourage employees to embrace it.

Supplementary Information The online version contains supplementary material available at https://doi.org/10.1007/s13178-021-00592-9.

Author Contribution FP designed the study, prepared the data for analysis, and wrote the initial draft of the study. CA prepared the data for analysis, conducted the data analysis, and wrote the initial draft of the study. WT provided input into the study design and data analysis and critically edited the draft. DEH provided guidance on the data and policy environment and critically edited the draft.

Funding This research was partially supported by the Australian Government through the Australian Research Council's Centre of Excellence for Children and Families over the Life Course (CE140100027).

Data, Materials, and/or Code Availability The data used in these analyses were provided by Pride in Diversity. Inquiries regarding the data access should be addressed to awei@ prideindiversity.com.au. The syntax code used to generate the findings presented in this study can be obtained from the lead author upon request.

\section{Declarations}

Ethics Approval The procedures used in this study adhere to the tenets of the Declaration of Helsinki. Approval for the AWEI Survey was provided by the ethics committee of ACON Health, whereas approval for the present study was obtained from the ethics committee of The University of Queensland (clearance number 2019003069).

Informed Consent Survey responses were de-identified prior to data analysis. All participants provided consent to the use of their responses for research purposes prior to completing the survey.

Conflict of Interest Francisco Perales, Christine Ablaza, and Wojtek Tomaszewski have no relevant financial or non-financial interests to disclose. Dawn Emsen-Hough would like to disclose that they are Director of Pride Inclusion Programs at ACON Health (a not-for-profit organization committed to diversity and inclusion in the workplace), as well as Chief Investigator of the Australian Workplace Equality Index Survey data used in this study. These roles and responsibilities, nevertheless, have not affected her involvement in the present research study.

Open Access This article is licensed under a Creative Commons Attribution 4.0 International License, which permits use, sharing, adaptation, distribution and reproduction in any medium or format, as long as you give appropriate credit to the original author(s) and the source, provide a link to the Creative Commons licence, and indicate if changes were made. The images or other third party material in this article are included in the article's Creative Commons licence, unless indicated otherwise in a credit line to the material. If material is not included in the article's Creative Commons licence and your intended use is not permitted by statutory regulation or exceeds the permitted use, you will need to obtain permission directly from the copyright holder. To view a copy of this licence, visit http://creativecommons.org/licenses/by/4.0/.

\section{References}

Acquavita, S. P., Pittman, J., Gibbons, M., \& Castellanos-Brown, K. (2009). Personal and organizational diversity factors' impact on social workers' job satisfaction: Results from a national internetbased survey. Administration in Social Work, 33(2), 151-166. https://doi.org/10.1080/03643100902768824

Ansara, Y. G., \& Hegarty, P. (2014). Methodologies of misgendering: Recommendations for reducing cisgenderism in psychological research. Feminism \& Psychology, 24(2), 259-270. https://doi. org/10.1177/0959353514526217

Australian Human Rights Commission. (2013). Sexual orientation, gender identity and intersex status discrimination. Australian Human Rights Commission, Sydney, NSW.

Commission, A. H. R. (2014). Face the facts Australian Human Rights Commission. NSW.

Badgett, M. V. L., Durso, L., Kastanis, A., \& Mallory, C. (2013). The business impact of LGBT-supportive workplace policies. The Williams Institute.

Badgett, M. V. L., Lau, H., Sears, B., \& Ho, D. (2007). Bias in the workplace: Consistent evidence of sexual orientation and gender identity discrimination. The Williams Institute.

Baker, R., Brick, J. M., Bates, N. A., Battaglia, M., Couper, M. P., \& Tourangeau, R. (2013). Summary report of the AAPOR task force on non-probability sampling. Journal of Survey Statistics and Methodology, 1(2), 90-105. https://doi.org/10.1093/jssam/smt008

Bates, T., Thomas, C. S., \& Timming, A. R. (2020). Employment discrimination against gender diverse individuals in Western Australia. Equality, Diversity and Inclusion, 40(3), 273-289. https:// doi.org/10.1108/EDI-04-2020-0073

Beauregard, T. A., Arevshatian, L., Booth, J. E., \& Whittle, S. (2018). Listen carefully: Transgender voices in the workplace. International Journal of Human Resource Management, 29(5), 857-884. https://doi.org/10.1080/09585192.2016.1234503

Birkett, M., Russell, S. T., \& Corliss, H. L. (2014). Sexual-orientation disparities in school: The mediational role of indicators of victimization in achievement and truancy because of feeling unsafe. American Journal of Public Health, 104(6), 1124-1128. https:// doi.org/10.2105/AJPH.2013.301785

Boekhorst, J. A. (2014). The role of authentic leadership in fostering workplace inclusion: A social information processing perspective. Human Resource Management, 54(2), 241-264. https://doi.org/ 10.1002/hrm.21669

Brolis, O., Courtois, M., Herman, G., \& Nyssens, M. (2018). Do social enterprises discriminate less than for-profit organizations? The influence of sector and diversity policies on managers' prejudice toward immigrants. Nonprofit and Voluntary Sector Quarterly, 47(4), 745-766. https://doi.org/10.1177/0899764018758461

Budge, S. L., Tebbe, E. N., \& Howard, K. A. S. (2010). The work experiences of transgender individuals: Negotiating the transition and career decision-making processes. Journal of Counseling Psychology, 57(4), 377-393. https://doi.org/10.1037/a0020472

Collins, J. C. (2015). Characteristics of "masculinized" industries: Gay men as a provocative exception to male privilege and gendered rules. Human Resource Development Review, 14(4), 415-441. https://doi.org/10.1177/1534484314559930

Collins, J. C., McFadden, C., Rocco, T. S., \& Mathis, M. K. (2015). The problem of transgender marginalization and exclusion: Critical actions for human resource development. Human Resource Development Review, 14(2), 205-226. https://doi.org/10.1177/ 1534484315581755

Collins, K. A., \& Clément, R. (2012). Language and prejudice: Direct and moderated effects. Journal of Language and Social Psychology, 31(4), 376-396. https://doi.org/10.1177/0261927X12446611 
Cottrill, K., Lopez, P., \& Hoffman, C. (2014). How authentic leadership and inclusion benefit organizations. Equality, Diversity and Inclusion, 33(3), 275-292. https://doi.org/10.1108/EDI-05-2012-0041

Cox, T. H. (1994). Cultural Diversity in Organizations: Theory, Research and Practice. Berrett-Koehler.

Day, N. E., \& Greene, P. G. (2008). A case for sexual orientation diversity management in small and large organizations. Human Resource Management, 47(3), 637-654. https://doi.org/10.1002/ hrm. 20235

Dietert, M., \& Dentice, D. (2009). Gender identity issues and workplace discrimination: The transgender experience. Journal of Workplace Rights, 14(1), 121.

Diversity Council Australia. (2016). Words at work: Building inclusion through the power of language. Diversity Council Australia.

Drydakis, N. (2019). Sexual orientation and labor market outcomes. IZA World of Labor, 111v2. https://doi.org/10.15185/izawol. 111.v2

Ferdman, B. M. (2014). The practice of inclusion in diverse organizations In B. M. Ferdman \& B. Deane (Eds.), Diversity at work: the practice of inclusion (pp. 3-54). San Francisco: Wiley.

Flores, A. R. (2015). Attitudes toward transgender rights: Perceived knowledge and secondary interpersonal contact. Politics, Groups \& Identities, 3(3), 398-416. https://doi.org/10.1080/21565503. 2015.1050414

Giffords, E. D. (2009). An examination of organizational commitment and professional commitment and the relationship to work environment, demographic and organizational factors. Journal of Social Work, 9(4), 386-404. https://doi.org/10.1177/ 1468017309346232

Goldberg, A. E., Kuvalanka, K. A., Budge, S. L., Benz, M. B., \& Smith, J. Z. (2019). Health care experiences of transgender binary and nonbinary university students. Counseling Psychologist, 47(1), 59-97. https://doi.org/10.1177/0011000019827568

Grant, J., Mottet, L., Tanis, J., Harrison, J., Herman, J., \& Keisling, M. (2010). National Transgender Discrimination Survey Report on Health and Health care.

Grant, J., Mottet, L., Tanis, J., Harrison, J., Herman, J., \& Keisling, M. (2011). Injustice at every turn: A report of the National Transgender Discrimination Survey. Washington.

Groeneveld, S. (2011). Diversity and employee turnover in the Dutch public sector: Does diversity management make a difference? International Journal of Public Sector Management, 24(6), 594612. https://doi.org/10.1108/09513551111163675

Grollman, E. A. (2017). Sexual orientation differences in attitudes about sexuality, race, and gender. Social Science Research, 61, 126-141. https://doi.org/10.1016/j.ssresearch.2016.05.002

Hanssmann, C., Morrison, D., \& Russian, E. (2008). Talking, gawking, or getting it done: Provider trainings to increase cultural and clinical competence for transgender and gender-nonconforming patients and clients. Sexuality Research \& Social Policy, 5(1), 5-23. https://doi.org/10.1525/srsp.2008.5.1.5

Institute of Medicine. (2011). The health of lesbian, gay, bisexual, and transgender people building a foundation for better understanding. National Academy of Sciences.

Ipsos. (2018). Global attitudes toward transgender people. Retrieved from https://www.ipsos.com/en/global-attitudestoward-transgender-people

Jackson, S. E., Joshi, A., \& Erhardt, N. L. (2003). Recent research on team and organizational diversity: SWOT analysis and implications. Journal of Management, 29(6), 801-830. https://doi.org/10. 1016/S0149-2063(03)00080-1

James, S. E., Herman, J. L., Rankin, S., Keisling, M., Mottet, L., \& Anafi, M. (2016). The report of the 2015 U.S. Transgender Survey. National Center for Transgender Equality, Washington, D.C.

Jones, T. (2016). Female-to-male (FtM) transgender employees in Australia. In T. Köllen (Ed.), Sexual Orientation and Transgender
Issues in Organizations: Global Perspectives on LGBT Workforce Diversity: Springer.

Kelly, M., Carathers, J., \& Kade, T. (2020). Beyond tolerance: Policies, practices, and ideologies of queer-friendly workplaces. Sexuality Research \& Social Policy. https://doi.org/10.1007/ s13178-020-00512-3

Kite, M., Togans, L., \& Schultz, T. (2019). Stability or change? A cross-cultural look at attitudes toward sexual and gender identity minorities. In K. Keith (Ed.), Cross-Cultural Psychology: Contemporary Themes and Perspectives (2nd ed.): John Wiley $\&$ Sons Ltd.

Lewis, D. C., Flores, A. R., Haider-Markel, D., Patrick, M., Barry, T., \& Jami, K. T. (2017). Degrees of acceptance: Variation in public attitudes toward segments of the LGBT community. Political Research Quarterly, 70(4), 861-875. https://doi.org/10.1177/ 1065912917717352

Mallory, C., Hasenbush, A., \& Sears, B. (2015). Discrimination and harassment by law enforcement officers in the LGBT community. The Williams Institute.

McFadden, C. (2015). Lesbian, gay, bisexual, and transgender careers and human resource development: A systematic literature review. Human Resource Development Review, 14(2), 125-162. https:// doi.org/10.1177/1534484314549456

Mor Barak, M. E. (2015). Inclusion is the key to diversity management, but what is inclusion? Human Service Organizations: Management, Leadership \& Governance, 39(2), 83-88. https://doi.org/10. 1080/23303131.2015.1035599

Mor Barak, M. E., Lizano, E. L., Kim, A., Duan, L., Rhee, M.-K., Hsiao, H.-Y., \& Brimhall, K. C. (2016). The promise of diversity management for climate of inclusion: A state-of-the-art review and meta-analysis. Human Service Organizations: Management, Leadership \& Governance, 40(4), 305-333. https://doi.org/10. 1080/23303131.2016.1138915

Nadal, K. L., Skolnik, A., \& Wong, Y. (2012). Interpersonal and systemic microaggressions toward transgender people: Implications for counseling. Journal of LGBT Issues in Counseling, 6(1), 55-82. https://doi.org/10.1080/15538605.2012.648583

National LGBT Health Alliance. (2013). Inclusive language guide: Respecting people of intersex, trans and gender diverse experience. National LGBT Health Alliance, Newtown, NSW.

Nishii, L. (2013). The benefits of climate for inclusion for genderdiverse groups. Academy of Management Journal, 56(6), 1754 1774. https://doi.org/10.5465/amj.2009.0823

OECD. (2020). Over the rainbow? OECD Publishing, Paris.

Ohlander, J., Batalova, J., \& Treas, J. (2005). Explaining educational influences on attitudes toward homosexual relations. Social Science Research, 34(4), 781-799. https://doi.org/10. 1016/j.ssresearch.2004.12.004

Ozturk, M. B., \& Tatli, A. (2016). Gender identity inclusion in the workplace: Broadening diversity management research and practice through the case of transgender employees in the UK. International Journal of Human Resource Management, 27(8), 781-802. https://doi.org/10.1080/09585192.2015.1042902

Ozturk, M. B., \& Tatli, A. (2018). Sexuality, gender identity and career journeys. In A. M. Broadbridge \& S. L. Fielden (Eds.) Research Handbook of Diversity and Careers: Edward Elgar Publishing.

Ozturk, M. B., Rumens, N., \& Tatli, A. (2020). Age, sexuality and hegemonic masculinity: Exploring older gay men's masculinity practices at work. Gender, Work \& Organization, 27(6), 12531268. https://doi.org/10.1111/gwao.12469

Panicker, A., Agrawal, R. K., \& Khandelwal, U. (2018). Inclusive workplace and organizational citizenship behavior: Study of a higher education institution, India. Equality, Diversity and Inclusion, 37(6), 530-550. https://doi.org/10.1108/EDI-03-2017-0054

Pasek, J. (2016). When will nonprobability surveys mirror probability surveys? Considering types of inference and weighting strategies as 
criteria for correspondence. International Journal of Public Opinion Research, 28(2), 269-291. https://doi.org/10.1093/ijpor/edv016

Patev, A. J., Dunn, C. E., Hood, K. B., \& Barber, J. M. (2019). College students' perceptions of gender-inclusive language use predict attitudes toward transgender and gender nonconforming individuals. Journal of Language and Social Psychology, 38(3), 329-352. https://doi.org/10.1177/0261927X18815930

Pepper, S. M., \& Lorah, P. (2008). Career Issues and workplace considerations for the transsexual community: Bridging a gap of knowledge for career counselors and mental health care providers. Career Development Quarterly, 56(4), 330-343. https://doi. org/10.1002/j.2161-0045.2008.tb00098.x

Perales, F. (2018). The cognitive roots of prejudice towards same-sex couples: An analysis of an Australian national sample. Intelligence, 68, 117-127. https://doi.org/10.1016/j.intell.2018.03.012

Perales, F., Bouma, G., \& Campbell, A. (2019). Religion, support of equal rights for same-sex couples and the Australian national vote on marriage equality. Sociology of Religion, 80(1), 107-129. https://doi.org/10.1093/socrel/sry018

Perales, F., \& Campbell, A. (2018). Who supports equal rights for same-sex couples? Family Matters, 100, 28-41.

Pettigrew, T. F., \& Tropp, L. R. (2006). A meta-analytic test of intergroup contact theory. Journal of Personality and Social Psychology, 90(5), 751-783. https://doi.org/10.1037/0022-3514.90.5.751

Pride in Diversity. (2019). 2020 Australian Workplace Equality Index - National Survey Data. ACON and Goldman Sachs.

Puckett, J. A., Cleary, P., Rossman, K., Mustanski, B., \& Newcomb, M. E. (2018). Barriers to gender-affirming care for transgender and gender nonconforming individuals. Sexuality Research \& Social Policy, 15(1), 48-59. https://doi.org/10.1007/s13178-017-0295-8

Reczek, C. (2020). Sexual- and gender-minority families: A 2010 to 2020 decade in review. Journal of Marriage and Family, 82(1), 300-325. https://doi.org/10.1111/jomf.12607

Richard, O. C., Roh, H., \& Pieper, J. R. (2013). The link between diversity and equality management practice bundles and racial diversity in the managerial ranks: Does firm size matter? Human Resource Management, 52(2), 215-242. https://doi.org/10.1002/hrm.21528

Riseman, N. (2019). Australia's history of LGBTI politics and rights. In D. Haider-Markel, (Ed.), Oxford Encyclopedia of LGBT Politics and Policy: Oxford University Press. https://doi.org/10.1093/ acrefore/9780190228637.013.1260

Roberge, M. É., \& van Dick, R. (2010). Recognizing the benefits of diversity: When and how does diversity increase group performance? Human Resource Management Review, 20(4), 295-308. https://doi.org/10.1016/j.hrmr.2009.09.002

Saunders, S., \& Easteal, P. (2013). The nature, pervasiveness and manifestations of sexual harassment in rural Australia: Does 'masculinity' of workplace make a difference? Women's Studies International Forum, 40, 121-131. https://doi.org/10.1016/j.wsif. 2013.05.013

Sawyer, K., Thoroughgood, C., \& Webster, J. (2016). Queering the gender binary: Understanding transgender workplace experiences. In T. Köllen (Ed.), Sexual Orientation and Transgender Issues in Organizations: Global Perspectives on LGBT Workforce Diversity: Springer.

Sels, L., De Winne, S., Maes, J., Faems, D., Delmotte, J., \& Forrier, A. (2006). Linking HRM and small business performance: An examination of the impact of HRM intensity on the productivity and financial performance of small businesses. Small Business Economics, 26, 83-101.

Shore, L. M., Randel, A. E., Chung, B. G., Dean, M. A., Holcombe Ehrhart, K., \& Singh, G. (2011). Inclusion and diversity in work groups: A review and model for future research. Journal of Management, 37(4), 1262-1289. https://doi.org/10.1177/0149206310385943

Smith, T., Son, J., \& Kim, J. (2014). Public attitudes towards homosexuality and gay rights across time and countries. NORC at the University of Chicago and The Williams Institute.

Sullivan, C. T. (2018). Majesty in the city: Experiences of an aboriginal transgender sex workers in Sydney, Australia. Gender, Place \& Culture, 25(12), 1681-1702. https://doi.org/10.1080/0966369X. 2018.1553853

Tee, N., \& Hegarty, P. (2006). Predicting opposition to the civil rights of trans persons in the United Kingdom. Journal of Community \& Applied Social Psychology, 16(1), 70-80. https://doi.org/10. 1002/casp.851

Thoroughgood, C., Sawyer, K., \& Webster, J. (2020). Creating a transinclusive workplace. Harvard Business Review, 98(2), 114-123.

Valfort, M.-A. (2017). LGBTI in OECD countries: A review. OECD Social, Employment and Migration Working Papers No. 198. OECD Publishing, Paris.

Valliant, R., \& Dever, J. A. (2011). Estimating propensity adjustments for volunteer web surveys. Sociological Methods \& Research, 40(1), 105-137. https://doi.org/10.1177/0049124110392533

Wright, H. H. (2016). Cognition, language and aging. John Benjamins Publishing Company.

Zimman, L. (2017). Transgender language reform. Journal of Language and Discrimination, 1(1), 84-105. https://doi.org/10.1558/ jld.33139

Publisher's Note Springer Nature remains neutral with regard to jurisdictional claims in published maps and institutional affiliations. 